\title{
O CONTROLE DO TRABALHO EM UM CALL CENTER DE COBRANÇA
}

\author{
WORK CONTROL IN A DEBT \\ COLLECTION CALL CENTER
}

\author{
Alessandra Rachid * \\ Marlucy Godoy Ricci** \\ Patrícia Saltorato ${ }^{\star * *}$
}

\section{Resumo}

O objetivo deste artigo é explorar como se dá a organização do trabalho em um call center de cobrança, identificando quais as principais fontes de controle sobre esta atividade e como os trabalhadores percebem e lidam com elas. Para isso, foi realizado um estudo de caso em uma empresa terceirizada que presta serviços de cobrança por telefone. $\mathrm{O}$ estudo contou, com entrevistas a funcionários de diferentes níveis hierárquicos dentro da empresa, observação do local de trabalho e análise documental. A literatura aponta que os trabalhadores em serviços que envolvem contato com clientes, como neste caso, sofrem o chamado "duplo controle" exercido, por um lado, pelas normas e regras da empresa e, por outro, pelas demandas específicas colocadas por cada cliente. As formas de controle identificadas na empresa pesquisada coincidem parcialmente com os resultados encontrados na literatura para call centers, mas também foram observadas formas de controle próprias do serviço de cobrança por telefone.

Palavras-chave: Organização do trabalho. Controle do trabalho. Operador de teleatendimento. Cobrança de dívidas.

\footnotetext{
Abstract

The purpose of this paper is to explore the work organization in a debt collection call center, identifying the main sources of control in this activity and how workers perceive and deal with them To do this, research was carried out in a company that provides collection services by telephone to other firms, by conducting 53 interviews with people from different

* Doutora em Engenharia de produção pela Universidade Federal de São Carlos (UFSCar). Atualmente é docente horista da Universidade Presbiteriana Mackenzie, Brasil. E-mail: marlucy@fmr.edu.br

** Doutora em Engenharia de Produção. Docente adjunto da UFSCar-Sorocaba, Brasil. E-mail: patrisal@ dep.ufscar.br

*** Doutora em Engenharia Mecânica pela Universidade Estadual de Campinas (Unicamp), Brasil. E-mail: arachid@ufscar.br
} 
hierarchical levels, as well as observation at the workplace and analyzing the company's documents. The literature indicates that workers in service involving contact with customers, as happen in this case, undergo the so called "dual control" exercised, on one hand, by the company standards and rules, and, by the other hand by the specific demands posed by each client.The ways of control identified in the company under investigation partially coincide with the results of other research in telemarketing, but ways of control specific to collection services were also observed.

Keywords: Work organization. Work control. Call center operators. Debt collection.

\section{Introdução}

O debate acadêmico acerca do trabalho em empresas de teleatendimento gira em torno de um conjunto de particularidades relacionadas à organização e ao controle. Uma quantidade significativa de pesquisas descreve e analisa o trabalho dos operadores nesse setor, ressaltando a presença de um controle do tipo "industrial" aplicado à área de serviços, sem respeitar a diferença de natureza existente entre ambos (BATT; DOELLGAST, 2005; BRAGA, 2006; DELBRIDGE, 1998; OLIVEIRA, 2004; ROSENFIELD, 2007; VENCO, 1999). A racionalização, nesse ramo, tem sido observada em diversas atividades, nos campos hospitalar, de telégrafos, de telefonia, bancário, entre outros (ZAMBERLAIN, SALERNO, 1983; GRÜN, 1995; SEGNINI, 1999). O teleatendimento, nesse contexto, desperta a atenção da mídia e do meio acadêmico devido a seu crescimento acelerado, à heterogeneidade de serviços prestados e à geração de empregos formais, absorvendo uma mão-de-obra predominantemente jovem, feminina e em situação de primeiro emprego. Um dos aspectos de interesse em relação a essa área envolve as diferentes formas de controle que atuam sobre o trabalhador, que moldam e padronizam seu comportamento em uma situação de trabalho que, em sua essência, é baseada na pessoalidade e individualidade de cada caso atendido. A pouca autonomia relegada aos operadores torna esta atividade um objeto de pesquisa privilegiado em relação à questão do controle. Dentro deste contexto, o objetivo deste artigo é explorar a organização do trabalho em uma empresa que presta serviços de cobrança por telefone, identificando as principais fontes de controle sobre os operadores e como estes percebem e lidam com elas.

Em relação à metodologia empregada, este trabalho pode ser classificado como uma pesquisa aplicada, de abordagem qualitativa, cujo objetivo, exploratóriodescritivo, foi buscado tanto por meio de uma abordagem teórica, empregando pesquisa bibliográfica e documental (fonte de dados secundária), quanto por uma abordagem empírica (fonte de dados primária), valendo-se, para tanto, de entrevistas e da observação participante em uma empresa de cobrança, contribuindo desta forma para a consolidação do estudo de caso apresentado adiante.

A abordagem empírica foi conduzida em uma empresa que presta serviços de cobrança por telefone, localizada no interior de São Paulo, e visou explorar as demandas impostas sobre os operadores. Foram inicialmente realizadas entrevistas com o diretor de comunicação e com o presidente da empresa, ambas para negociar 
a realização da pesquisa e, também, para obter informações referentes aos serviços prestados, principalmente a respeito de clientes e investimentos. Posteriormente, foram realizadas, durante quatro meses, outras 51 entrevistas com trabalhadores de diferentes níveis hierárquicos, totalizando, ao fim da pesquisa, 53 entrevistas. As conversas se deram em uma sala de reuniões reservada para essa finalidade e duraram, em média, 30 minutos. Outras visitas à empresa também foram realizadas, com fins de observação do funcionamento da área operacional.

O Quadro 1 sumariza os cargos dos entrevistados. Com exceção do presidente e do diretor de comunicações, os demais entrevistados ingressaram na empresa como operadores, inclusive o gerente de operações que, durante a realização da pesquisa, foi promovido a diretor de operações. Durante a pesquisa procurou-se entrevistar pessoas que trabalhassem a mais tempo ne empresa, por isso houve um número significativo de entrevistados que já não ocupava mais o cargo de operador.

Quadro 1 - Cargos dos entrevistados

\begin{tabular}{lrr}
\hline Cargo Ocupado & Área & $\begin{array}{r}\text { Quantidade de } \\
\text { Entrevistados }\end{array}$ \\
\hline Presidente & Direção & 1 \\
Diretor de Comunicação & Procedimentos Gerais & 1 \\
\hline Assistente de backoffice & & 3 \\
Auxiliar & & 5 \\
\hline Gerente de operações & 1 \\
Monitor & Operação & 7 \\
Analista de qualidade & 15 \\
Operador de teleatendimento & 20 \\
\hline Total de entrevistas & & 53 \\
\hline
\end{tabular}

Fonte: Elaborado a partir das entrevistas.

Para as entrevistas com o presidente, o diretor de comunicação e o gerente de operações, foram utilizados roteiros específicos. As demais entrevistas seguiram um roteiro semiestruturado e tiveram o objetivo de traçar o perfil dos entrevistados no que se refere a gênero, idade, escolaridade, tempo de empresa e atividades desenvolvidas pelos operadores. 
A seguir, apresenta-se, primeiramente, um panorama do crescimento das empresas de teleatendimento no Brasil, da organização do trabalho nesta atividade e das diferentes formas de controle sobre o operador, e, em seguida, o estudo de caso realizado.

\section{Revisão da literatura sobre teleatendimento}

Segundo Sakamoto (2001), um call center, ou uma central de teleatendimento, é, de acordo com a designação do Instituto Brasileiro de Geografia e Estatística (IBGE), o lugar onde uma volumosa quantia de chamadas é feita ou recebida com o objetivo de apoiar processos de vendas, marketing, serviços ao cliente, cobrança, suporte técnico ou outras atividades específicas, o que destaca, dessa maneira, a enorme variedade de serviços prestados por meio do serviço.

Tonet (2007) aponta que o teleatendimento surgiu nos EUA quando a empresa Ford foi obrigada, por uma decisão judicial de 1968, a manter um serviço telefônico gratuito para o registro de reclamações sobre defeitos em seus veículos. No Brasil, as experiências pioneiras foram realizadas pelas empresas Credicard, Rhodia e Sadia, na década de 1980, o que posteriormente se popularizou através dos serviços de atendimento ao cliente (SAC) (SILVEIRA, 2006). A tecnologia da informação permitiu a criação de atividades de natureza diferenciada que foram reunidas em uma única central, e também viabilizou a comercialização internacional, que antes era considerada inviável, sob a prática atualmente conhecida como offshore..

O mercado brasileiro de teleatendimento se consolidou a partir dos anos 1990. Entre 2000 e 2004, o faturamento deste mercado cresceu de US\$ 520 milhões para US\$ 3 bilhões (OLIVEIRA, 2005). O site callcenter.inf.br mantem sistematizadas e atualizadas informações relativas à empresas do setor que autorizam a publicação de dados sobre seu desempenho. A Tabela 1 apresenta os dados deste site para os anos selecionados desde 1999.

Tabela 1 - Faturamento das empresas de teleatendimento (Brasil, anos selecionados)

\begin{tabular}{rr}
\hline Ano & $\begin{array}{r}\text { Faturamento } \\
\text { Bruto }^{(1),(2)}\end{array}$ \\
\hline 1999 & 96,9 \\
2000 & 484,1 \\
2005 & 4179,9 \\
2010 & 8568,0 \\
2015 & 4841,1 \\
\hline
\end{tabular}

Fonte: callcenter.inf.br, 2017. 
Notas: (1) Valores em Reais, (2) Faturamento bruto em milhões de Reais

A Tabela 2, também construída com base nas informações do site supracitado, apresenta o número de postos de atendimento, de operadores e o total de funcionários dessas empresas. Ainda que se observe uma estabilização a partir de 2015, os dados reforçam o forte crescimento desta atividade nos anos anteriores, o que foi apontado por vários pesquisadores (BAGNARA, MARTI, 2001; GEORGES, 2006; VENCO, 2006).

Tabela 2 - Quantidade de postos de atendimento, operadores e funcionários

(Brasil, anos selecionados)

\begin{tabular}{rrrr}
\hline Ano & Postos de Atendimento & Operadores & Total de Funcionários \\
\hline 1999 & 5.083 & 1.374 & 1.378 \\
2000 & 14.450 & 3.058 & 3.058 \\
2005 & 107.715 & 195.743 & 237.690 \\
2010 & 196.967 & 316.018 & 388.262 \\
2015 & 267.937 & 442.214 & 528.550 \\
2016 & 267.718 & 441.637 & 527.288 \\
2017 & 267.276 & 439.212 & 523.352 \\
\hline
\end{tabular}

Fonte: callcenter.inf.br, 2017.

Apesar da diversificação dos serviços prestados, a atividade realizada pelos operadores de teleatendimento apresenta vários aspectos em comum, dentre os quais se destaca o forte controle sobre eles. As discussões teóricas relacionadas ao controle sobre o trabalhador ganharam força com os autores críticos do processo de trabalho (BRAVERMAN, 1974; BURAWOY, 1983), estando presentes tanto nas proposições baseadas nos princípios sociotécnicos (TRIST, 1981; BIAZZI, 1994; SALERNO, 1999) quanto nas discussões mais recentes sobre as novas formas de controle, cada vez mais sutis e sofisticadas, porém não menos presentes ou opressoras (SMITH, 1997; BATT, DOELLGAST, 2005).

Dentre tais formas difusas/sutis está a criação de equipes de trabalho cujo desempenho é constantemente monitorado pela empresa. Para Zarifian (2001), o sucesso das equipes depende da ação de cada um, o que pode se constituir em uma rede de pressão e controle entre os próprios colegas. Tem-se, nesse contexto, uma situação de controle horizontal de todos sobre todos, não menos constrangedora do que as formas verticalizadas. Segundo Burawoy (1979), as regras não são impostas apenas por coerção, mas com frequência por um consentimento construído entre os gerentes e os trabalhadores. De acordo com Castro e Guimarães (1991), um aspecto 
relevante neste caso é o significado cultural e simbólico partilhado por eles, que age como um fator disciplinador e motivador de sujeição à dominação. Há, dessa maneira, uma captura da subjetividade dos trabalhadores, ou seja, a produção de consentimento, por meio desses "novos coletivos" - as equipes que colaboram com a gestão -, ao mesmo tempo em que há também um enfraquecimento da organização coletiva, como ressaltado por Alves (2011).

No contexto da atividade estudada, há, ainda, o potencial conflito derivado da atitude exigida e da emoção sentida quando do atendimento ao cliente. Os atendentes precisam permanecer calmos, mesmo sob pressão, ter atitudes positivas e escuta ativa, ser pacientes e empáticos, mesmo quando o cliente estiver irritado, situação bastante frequente. O operador precisa manter uma postura de "fachada", como apontado por Bateson e Hoffman (2001) e Hochschild (1983) ao analisarem o trabalho desempenhado por aeromoças. Por outro lado, a experiência destes trabalhadores em sua atividade pode levá-los a desenvolver estratégias de regulação e compensação. Para Guerín et al. (2001), a interação com o meio resulta de um processo de apropriação e de releitura da prescrição sobre o trabalho, de acordo com os objetivos que o trabalhador coloca para si em função da situação. A elaboração de um método próprio para facilitar a execução é uma forma de aliviar a carga de trabalho e cumprir com o que foi prescrito, garantindo o êxito (CASTRO, GUIMARÃES, 1991). Dejours (1987) chama tais adaptações de "macetes", ou seja, estratégias que permitem regular o trabalho às situações reais e, assim, dar conta das tarefas, ao mesmo tempo em que se preserva e alivia a sensação de sofrimento. Em outras palavras, as novas formas de controle não se impõem "sem resistências e lutas cotidianas" (ALVES, 2011, p. 14).

O debate acadêmico acerca do trabalho nas empresas de teleatendimento gira em torno de um conjunto de particularidades relacionadas à organização e ao controle. A função central dos operadores de teleatendimento é atender e/ou realizar chamadas telefônicas, porém vem se tornando mais diversificada, na medida em que os operadores devem atualizar cadastros de clientes, procurar suas informações, registrar a conversa no sistema e, ainda, cumprir metas de ligações e/ou de vendas, por exemplo.

As informações entram na área da operação por meio do sistema de distribuição de chamadas, a Unidade de Resposta Audível (URA), que alimenta o sistema de informação do operador, ou seja, o seu terminal de computador. No monitor, ficam disponíveis informações sobre o cliente, sua demanda, número e desfecho de ligações anteriores. Há, ainda, um espaço para que o operador anote o andamento da conversa e seu fechamento, e se a demanda foi ou não atendida. Com a automação do atendimento, o próprio cliente utiliza as teclas do telefone para executar as atividades estruturadas e passíveis de eletronização. Para as demandas não estruturadas, o cliente solicita o contato com o operador, o que significa que este terá que lidar com demandas específicas e "parcialmente" inesperadas, forma como Zarifian (2001) se refere a tarefas que não podem ser totalmente predeterminadas.

A automação imprime um ritmo próprio à atividade de trabalho do operador de teleatendimento, já que visa contribuir para a eliminação de tempos mortos entre tarefas e aumento de velocidade de execução, como pode ser verificado 
no tempo entre uma chamada e outra, denominado "temporização" (DURAND, 2004). Segundo Venco (2006), a temporização oscila entre 7 e 20 segundos na França, permitindo descansos de apenas 5 a 12 minutos por hora. Respondendo a uma demanda criada para esta pesquisa, o site Guia Call Center Brasil realizou um levantamento sobre temporização por meio de uma enquete que ficou disponível por 11 dias, tendo sido respondida voluntariamente por operadores que acessaram o site. Os resultados são apresentados na Tabela 3.

Tabela 3 - Temporização na operação (Brasil)

\begin{tabular}{lrr}
\hline Pausa entre uma ligação e outra & Total de respondentes & \% \\
\hline Sem pausa & 9.747 & 28,5 \\
1 a 10 segundos & 10.810 & 31,6 \\
11 a 15 segundos & 4.076 & 11,9 \\
16 a 20 segundos & 2.127 & 6,2 \\
Superior a 20 segundos & 7.442 & 21,8 \\
\hline Total & $\mathbf{3 4 . 2 0 2}$ & $\mathbf{1 0 0 , 0}$ \\
\hline
\end{tabular}

Fonte: Levantamento do Guia Call Center Brasil para esta pesquisa.

A relação entre tecnologia e intensificação da carga de trabalho e do controle tem sido bastante explorada pela literatura (BURAWOY, 1983; CASTRO, GUIMARÃES, 1991; GITHAY, 1994; SALERNO, 2004). No caso dos operadores, observa-se que o fluxo intenso de ligações é resultado da inserção da tecnologia da informação, que contribui para o controle do trabalho. Para padronizar o contato entre o operador e o cliente, existe o chamado script, um roteiro imposto pelas empresas que caracteriza a prescrição da atividade para o operador. Segundo Oliveira (2005), cerca de 30\% dos serviços próprios de teleatendimento e $42 \%$ dos terceirizados utilizam tal script, o que contribui para tornar o trabalho extremamente rotineiro e restringe a autonomia dos trabalhadores (VENCO, 1999).

$\mathrm{O}$ operador tem que manter os olhos fixos na tela do computador, que indica o tempo de duração da ligação e a quantidade de clientes em espera. Desta forma, o controle se mantém presente durante toda a jornada de trabalho e se estende para além dela, já que as ligações são gravadas e podem ser posteriormente verificadas. $O$ trabalho é desempenhado em um compartimento denominado posto de atendimento, ou baia, separado dos outros por divisórias, “[...] de forma a manter os operadores protegidos de interferências externas, como barulhos e conversas paralelas" (SILVEIRA, 2006, p. 48). Esta separação dificulta o contato visual entre eles. As baias ficam enfileiradas na área operacional, sob o olhar de gerentes e monitores. A ausência de salas individualizadas é chamada por Barnes (2007) de open-play layout. 
Foucault (1987), ao analisar prisões, hospitais, fábricas, escolas e quartéis, observa como o espaço físico é coadjuvante no processo disciplinador, permitindo

[...] realizar uma vigilância ao mesmo tempo geral e individual; constatar a presença, a aplicação do operário, a qualidade de seu trabalho; comparar os operários entre si; classificá-los segundo sua habilidade e rapidez; acompanhar os sucessivos estágios da fabricação (FOUCAULT, 1987, p. 124).

Segundo o autor, as áreas "sem paredes" constituem espaços nos quais se potencializa uma rede de olhares que permite que todos controlem todos. O autor se refere a esse controle visual como o "olhar hierárquico" (FOULCAULT, 1987, p. 143). No caso do teleatendimento, o espaço de trabalho viabiliza a visão dos operadores pelos gerentes e monitores, constituindo mais um elemento de controle. $\mathrm{O}$ poder disciplinador ou "biopoder", segundo Foucault (2001), produz o comportamento desejado para o funcionamento e manutenção da sociedade industrial, e a vigilância permanente sobre os indivíduos controla o tempo e maximiza a produção. Para Braga (2006), o script, o isolamento físico e o grande fluxo de informações representam constrangimentos que tornam o teleatendimento um campo privilegiado para observar as contradições contemporâneas do trabalho. Além disso, esta é uma atividade que tem sofrido um forte processo de racionalização em função dos avanços tecnológicos. Braverman (1974) já argumentava que a tecnologia faz prevalecer, no setor de serviços, as mesmas normas de rotinização, fragmentação e desqualificação do trabalho vigentes na indústria.

A intensificação das formas de controle no trabalho do operador de teleatendimento tem fomentado discussões sobre o caráter taylorista desta atividade. De um lado, alguns autores ressaltam que ela não seria adequada aos métodos tayloristas, já que sua natureza, que consiste em fornecer informações variadas aos clientes, difere daquela em que tais métodos são aplicados (HOLTGREWE, KERST, 2001; TAYLOR, BAIN, 1999; TONET, 2007). Por outro lado, Oliveira (2004) salienta que este trabalho é marcado por um forte controle de conduta que determina seu ritmo, suas cadências e seus procedimentos, e por pouco espaço de autonomia, o que revela a presença dos princípios tayloristas. Venco (1999) também concorda com esta ideia e ressalta que há “[...] a divisão entre execução e concepção, o controle dos tempos e movimentos e a seleção científica dos trabalhadores” (VENCO, 1999, p. 63). Para Rosenfield (2007), o legado taylorista é identificado, uma vez que:

Os tempos são cronometrados nos segundos, inclusive as pausas e a produtividade, com mais precisão do que era possível no trabalho taylorista; há um forte controle dos movimentos e dos gestos, uma vez que o atendente fica preso ao head fone e seu escopo de movimentação restringe-se ao alcance do fio; o próprio processo de trabalho é constantemente monitorado e controlado por meio da gravação das ligações, da supervisão em tempo real, das auditorias, [...] operadores devem se remeter sempre à supervisão e nunca aos pares (ROSENFIELD, 2007, p. 452-453). 
Ainda nesse sentido, Batt e Doellgast (2005), e Braga (2006) e Delbridge (1998) concluem que este é um trabalho que testemunha como nenhum outro a taylorização intelectual. Em função disso, alguns autores classificam as empresas de teleatendimento como uma nova linha de montagem, com um controle ainda mais tirânico (TAYLOR; BAIN, 1999) ou como o sweatshop do século XXI, nesse caso referindo-se a condições precárias de trabalho (AZEVEDO; CALDAS, 2002).

No teleatendimento, podem ser observadas as três formas de controle do trabalho identificadas por Edwards (1979): (i) coerção personalizada, exercida pela própria organização, no caso daquele realizado pelos gerentes e monitores; (ii) controle técnico, exercido pelo equipamento que dirige o processo de trabalho e impõe seu ritmo, no caso daquele exercido pelos sistemas de informação; e (iii) controle burocrático, implicado nas relações sociais nos locais de trabalho e na estrutura social das empresas, com o tratamento do fluxo intenso de informações nas centrais norteado pelo tempo de duração das ligações e, também, por metas como quantidade de ligações atendidas e/ou efetuadas; quantidade de produtos/ serviços vendidos, no caso de televendas; quantidade de respostas fornecidas e reclamações registradas, no caso do atendimento ao consumidor; quantidade de retorno financeiro obtido pelo operador, no caso de centrais de vendas e de cobrança (AZEVEDO, CALDAS, 2002; ROSENFIELD, 2007; VENCO, 2006; VILELA, ASSUNÇÃO, 2004). O controle, nesses casos, é exercido pela organização em conjunto com os clientes, na medida em que estes colocam em pauta suas demandas específicas. Esse duplo controle, tipicamente vivenciado pelos trabalhadores que atuam na linha de frente dos serviços, é vivenciado também pelos operadores de teleatendimento (KORCZYNSKI et al., 2000).

\section{Trabalho e controle em uma empresa de cobrança}

O estudo de caso que ampara este artigo foi realizado em uma empresa que presta serviço de cobrança por telefone para os setores financeiro, de telefonia e varejo. A área operacional da empresa é dividida em atendimento ativo, que efetua as ligações para os devedores, e atendimento receptivo, que as atende. Normalmente, as ligações deste último setor provêm de pessoas inadimplentes que tomam a iniciativa de retornar contatos anteriormente realizados. Segundo dados da empresa, $79 \%$ dos operadores atuam no atendimento ativo e $21 \%$ no receptivo.

A rotina de trabalho baseia-se na negociação das dívidas com os inadimplentes. Os operadores entram em contato e apresentam propostas de quitação ou parcelamento previamente definidas, de acordo com a faixa de atraso, bem como opções de novas datas para o pagamento. Quando o inadimplente aceita a proposta, o operador dá a ordem de emissão de novo boleto ao backoffice, área de apoio à operação. Ao acessar a ficha do inadimplente na tela de seu computador, o operador visualiza as possibilidades de desconto e datas disponíveis para pagamento, que são estipuladas pelos bancos clientes, como esclarece um entrevistado: 
O padrão de cobrança/negociação é o de cada carteira. Por exemplo, a gente tinha a carteira do Banco X, que divide a cobrança em faixas de atraso: 10, 15 e 20 dias. Se você atrasou o seu carro em 15 dias, os operadores ligam para dar um aviso. Não é cobrança, é apenas um aviso. No caso dessa carteira, os operadores se identificam como sendo do Banco X e não do Call Center. Em outras carteiras, os operadores se identificam como sendo do Call Center (Entrevista 1, analista da qualidade 1, julho de 2007).

Cada banco cliente terceiriza para a empresa uma 'carteira' de produtos a serem cobrados. Em cada carteira, os operadores são divididos segundo esses 'produtos': veículos ou massificados (como são chamadas as dívidas de cartão de crédito, conta corrente, cheques e promissórias). Os operadores são divididos, ainda, por faixas de atraso, de forma que, por exemplo, alguns só realizam a cobrança dos massificados na faixa de 10 dias de atraso, e assim por diante. O layout da operação reflete estas divisões, como ilustra a Figura 1.

Figura 1 - Organização física da operação

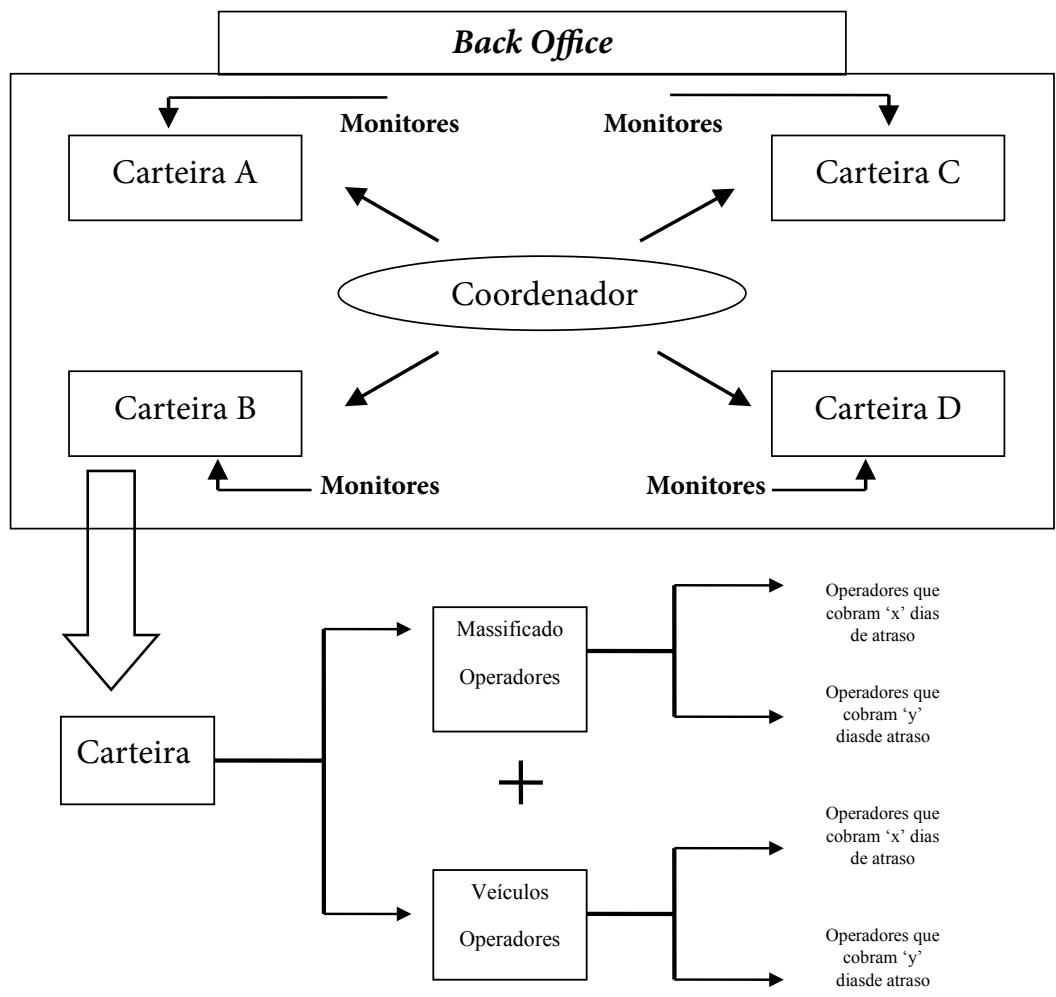

Fonte: Elaborado pelas autoras a partir das entrevistas. 
Cada carteira tem um coordenador, ou gestor, que busca garantir o cumprimento da estratégia de cobrança. A atividade do operador é controlada pelo sistema operacional, que compila o tempo e a quantidade de ligações realizadas. Existem, ainda, os monitores, que controlam a hora da entrada, do lanche e da saída dos operadores, suas vestimentas (se estão vestidos de avental) e sua produção horária, além de repassarem avisos da coordenação e da gerência. Sobre a responsabilidade dos monitores, um operador comentou:

Eles são responsáveis pela operação como um todo. Por exemplo, se o operador atrasou ou se o rendimento não está sendo de acordo com o esperado, ele tenta intervir, entender o que está acontecendo (Entrevista 4, operador, julho de 2007).

Sobre o tempo para o lanche, que passou de 15 para 30 minutos, uma operadora afirmou:

Quando eu era operadora, o intervalo era de 15 minutos, um intervalo pequeno em que você comia rápido, nem fazia a digestão e voltava para o posto de atendimento. Agora, o período é maior. São 30 minutos. Aumentou, mas não é muito diferente, porque esses 30 minutos são divididos em 15 minutos e depois mais 15 minutos (Entrevista 33, auxiliar de normas e procedimentos, julho de 2007).

Os monitores também acompanham o desempenho dos operadores por meio da escuta das ligações. Para um dos entrevistados, analista da qualidade, no entanto, o objetivo dessa escuta não é controlar:

A monitoria tem acesso aos gravadores dos ramais. Eles trabalham com os gravadores, com a escuta mesmo. É importante, caso surja alguma divergência. Por exemplo, o cliente está falando alguma coisa e o operador outra. Aí a gente vai lá e escuta para ver se procede ou não (Entrevista 1, analista da qualidade, julho de 2007).

Isso foi confirmado na entrevista com um operador, quando diz que "Os monitores ajudam quando o operador está com algum cliente na linha e surge alguma dúvida" (Entrevista 4, operador, junho de 2007).

No caso da empresa pesquisada, o script não é tão rígido, pois a atividade do operador envolve a negociação com os inadimplentes. Segundo o gerente de operações, o objetivo do script é padronizar a "abertura" da ligação, na qual o operador deve informar o motivo do contato, e o "fechamento", com critérios como "cordialidade", "tratamento personalizado" e "posicionamento do cliente". O operador que não respeitar esses critérios perde pontuação em sua ficha de avaliação. Os trechos a seguir ilustram a preocupação com esses critérios: 
O script existe para mostrar respeito ao cliente [inadimplente]. A gente pede ao operador para que ele posicione o cliente para quando precisar pausar a ligação, por exemplo, - "Senhora, aguarde um minuto que eu vou buscar a informação". A ligação começa com a apresentação e termina com um encerramento, como "boa tarde" ou "bom dia". Tem tratamento personalizado, pois a gente pede para o operador que ele chame o cliente pelo nome durante a negociação, porque isso faz com que o cliente se sinta mais à vontade (Entrevista 2, analista da qualidade, agosto de 2007).

Têm as regras de como falar com o devedor, de não 'xingar', de não usar gírias, não discutir com o devedor, não alterar a voz. Regras normais (Entrevista 22, monitor, agosto de 2007).

A atividade sofre imprevistos próprios de serviços de "linha de frente" e o operador precisa desenvolver meios para lidar com as diferentes demandas e reações que surgem dentre os inadimplentes. Os operadores têm que ser flexíveis, considerando que se trata da negociação de dívidas:

Eu negocio com o cliente [inadimplente] e tem que ter muito jogo de cintura (Entrevista 50, operadora, julho de 2007).

Existe todo tipo de cliente: cliente brabo, cliente calmo, cliente nervoso ...e você tem que saber dobrar. É assim. O atendimento é a base. Você atende o cliente e tenta solucionar ali o problema (Entrevista 2, analista da qualidade, junho de 2007).

Os operadores têm que desenvolver competências para lidar com situações não previstas e, ao mesmo tempo, respeitar os padrões fixados pela empresa e pelos bancos clientes. Eles lidam com uma gama variada de inadimplentes que têm diferentes disposições sobre seus débitos e devem manter uma postura cordial, de "fachada", como apontado na revisão da literatura apresentada. Nas palavras de um monitor "Por mais que ele (inadimplente) chame sua mãe de 'santa', você tem que aceitar e tentar contornar aquilo ali" (Entrevista 24, monitor, junho de 2007).

Os operadores precisam permanecer calmos, mesmo quando o inadimplente estiver irritado ou quando se identificam com suas dificuldades, o que torna o trabalho mais cansativo:

O trabalho do operador é cansativo, é exaustivo, é maçante, porque todo dia você faz a mesma coisa. Tem que ligar e tem que cobrar e ligar para clientes chatos, clientes que te tratam mal. É um trabalho cansativo (Entrevista 41, operadora, julho de 2007).

Como apontado anteriormente, os operadores da empresa pesquisada têm que seguir as normas definidas por cada banco cliente, as chamadas "campanhas", 
que correspondem aos descontos de acordo com o tempo de atraso da dívida, com os procedimentos diferenciados entre os produtos massificados e veículos. Segundo os operadores,

Cada banco tem uma campanha e procedimentos de cobrança. Por exemplo, com 50 dias de atraso é feito uma notificação/aviso de cobrança. Se o devedor não paga a dívida ou não é localizado, temos que dar andamento a uma busca do bem. Tem bancos que não dão desconto nenhum para o devedor. Então, as campanhas são bem diferentes e temos que ficar atentos a isso para não errar (Entrevista 21, monitor, agosto de 2007).

Além dessas regras, há três diferentes metas a serem cumpridas: a quantidade de ligações diárias; a quantidade de boletos gerados ao dia e as metas de honorários, que são o retorno financeiro das dívidas resgatadas. Os operadores, no entanto, percebem que os pesos atribuídos a essas metas são diferentes:

As metas de boletos gerados e pagos contam muito. Eu percebi que [...] eu fazia muito boleto, mas nunca chegava no número de ligações e nunca ninguém me chamou para reclamar (Entrevista 38, auxiliar de normas e procedimentos, agosto de 2007).

Um entrevistado comentou a forte pressão por gerar mais boletos:

Você precisa gerar mais boleto e é aquela cobrança, diariamente, de boletos, boletos, boletos... Você vai tirar boleto de onde? [...] Se a gente não bate as metas, nós perdemos os contratos. Os bancos clientes passam os contratos para outra assessoria. Nossa, a gente se sente pressionadíssimo! É um desespero (Entrevista 22, monitor, junho de 2007).

Os operadores sentem-se constantemente pressionados a cumprir as metas, mas quando as cumprem, o prazer não perdura, já que estas, quando atingidas, são elevadas: "A meta aumenta mensalmente, ou seja, se você bateu a meta, ela sobe. Não é fácil, é complicado" (Entrevista 22, monitor, junho de 2007). "Na verdade, por mais que você faça, faça, faça, nunca tá bom" (Entrevista 36, analista da qualidade, julho de 2007). "Nunca está bom. Sempre tem que fazer mais e mais" (Entrevista 32, operadora, agosto de 2007).

Os operadores de uma mesma carteira, ou seja, que trabalham para um mesmo banco cliente, são considerados uma equipe e ficam próximos uns dos outros, como mostrado na Figura 1. Operadores e equipes que cumprem as metas recebem prêmios, que podem ser em dinheiro, recebidos junto com o salário, ou brindes:

Quando a meta é batida, você tem premiações em dinheiro e têm os prêmios que os bancos mandam, como camiseta, boné, um almoço com o presidente da empresa [de teleatendimento]. São coisas para incentivar. Eles dão bombons, pão de queijo... (Entrevista 22, monitor, agosto de 2007). 
Até o mês passado, a carteira que atingisse a meta de honorários definida pelo call center ganhava R \$130,00 no salário. Então, os operadores correm atrás (Entrevista 19, monitor, junho de 2007).

Esse valor é significativo, considerando que o salário médio dos operadores era de $\mathrm{R} \$ 550,00$ na época da pesquisa. Surge, dessa forma, uma pressão entre os operadores da mesma equipe: "É difícil saber que só um na equipe faz o trabalho e o restante fica ali sem fazer esforço" (Entrevista 21, monitor, julho de 2007).

Se você não bateu sua meta individual diária, você prejudica sua equipe toda. Se você não tiver indo de acordo com o que a equipe está trabalhando e se for uma diferença muito grande, você vai se queimar com a sua equipe (Entrevista 22, monitor, agosto de 2007).

Essa pressão se configura como mais uma forma de controle, como apontado por Zarifian (2001), o que, na empresa pesquisada, tem levado à insatisfação: " $E$ aquela rixa, aquela briga. Eu acho que ali, na operação, o que mais a gente vê são as pessoas tristes por causa desse clima de competição" (Entrevista 22, monitor, junho de 2007).

O estudo permitiu identificar um aspecto específico da atividade de cobrança que não havia sido observado na revisão da literatura. Numa tentativa de afastar o estigma negativo associado a esta atividade, a função recebe, na empresa pesquisada, a designação de "recuperador de créditos", usada por gerentes, monitores, controladores e pelos próprios operadores:

Quando comecei na cobrança, pensei: 'nossa, eu vou fazer cobrança no telefone!' Não me via nessa situação, mas, depois [...] você vê a pessoa, com aquele peso todo nas costas, e você oferece uma opção de pagamento e consegue um refinanciamento. Você está ajudando a pessoa. Aí, eu comecei a enxergar o outro lado e ter uma desenvoltura melhor na minha função. É um trabalho muito importante no mercado. Um recuperador de crédito vai recuperar o crédito de quem está inadimplente no mercado [...] Quanto mais pessoas inadimplentes o mercado tiver, maiores serão os juros e menos dinheiro os bancos terão para emprestar. Então, os recuperadores é que vão permitir com que os bancos possam continuar emprestando dinheiro (Entrevista 20, monitora, agosto de 2007).

Essa ressignificação ajuda os operadores a legitimarem, inclusive para si mesmos, a atividade que desempenham, contribuindo para o aspecto simbólico compartilhado por gerentes e trabalhadores apontado por Castro e Guimarães (1991). Esse processo se torna ainda mais significativo uma vez que, muitas vezes, os operadores se identificam com os inadimplentes e suas dificuldades financeiras. Ao atribuir um sentido positivo à atividade que desempenham, torna-se mais aceitável realizá-la, conforme afirmam os operadores: 
Você liga para o cliente [inadimplente] e não fala pra ele que ele está devendo. Você liga e informa que tem uma campanha de desconto porque, assim, além do cliente não ser grosso com você, você acabava ajudando ele, porque o cliente quer ser ajudado, não quer ser cobrado (Entrevista 26, operadora, junho de 2007)

A gente tem como objetivo, eu acredito, retomar o crédito para os clientes voltarem a ter suas atividades normais, entendeu? Poder fazer uma compra. Então, sempre trabalhamos focando no cliente, para estar tentando regularizar a situação dele (Entrevista 30, operador, julho de 2007).

Outro aspecto que ajuda nesse processo de não se ver como cobrador é a tecnologia da informação, que viabiliza a substituição do cobrador tradicional, de porta em porta, pela "telecobrança", tornando a atividade mais discreta, mais "privada”, por ser substituída por telefonemas. Uma consequência da competição descrita anteriormente dentro das equipes é a dificuldade na construção de formas coletivas de defesa contra a dominação, como apontado por Alves (2011). Isso não impede, no entanto, que os operadores desenvolvam, de maneira individual, meios para se proteger ou minimizar o sofrimento no trabalho como, por exemplo, as estratégias e "macetes" apontados por Castro e Guimarães (1991), Dejours (1987) e Guerín et al. (2001). Dois entrevistados revelam o uso de um recurso do sistema operacional, a tecla mute, para evitar o desgaste psicológico diante de certas reações dos inadimplentes. Ao apertar a tecla mute, a ligação fica "muda" e nem o operador nem o inadimplente ouvem:

Você liga todo dia na casa do cara. Ele quer estressar mesmo, mas quando eu trabalhava na operação, eu pensava: "problema é dele, tá devendo, vou ligar". Aí ligava e quando ele começava a xingar, a estressar, eu levava mais no lado da brincadeira, dava risada e apertava o mute e não ouvia mais absurdo. Porque tem cada absurdo! (Entrevista 29, analista da qualidade, agosto de 2007)

Eu nunca misturei serviço com vida pessoal. [...] Dou risada. Vou falar o que pro cara? Eu coloco no mudo e dou risada e deixo ele me xingar. É ele que está estressado. Tem gente que não consegue fazer essa separação. No meu caso, eu ainda tirava sarro das coisas. Não ficava grilada com o que o cara lá da Bahia falou. Ele nem sabe quem eu sou (Entrevista 37, analista da qualidade, junho de 2007).

Essas são algumas artimanhas que os operadores constroem, de forma mais ou menos consciente, para compatibilizar os objetivos da produção, sua competência e a preservação de sua saúde. Outras estratégias são claramente usadas para criar folgas no ritmo de trabalho:

É importante não ficar brincando, não ficar lixando as unhas.Vamos trabalhar! Mas eu acho que precisa dar uma 'desfocada' e eu fazia isso (Entrevista 4, operador, agosto de 2007). 
Tem aqueles dias em que você não está muito afim. Aí você pega aqueles números de telefone que nunca atendem e faz as ligações. Assim, você cumpre com a meta de ligações e ninguém vem reclamar (Entrevista 41, operadora, junho de 2007).

Como diz uma operadora, "Não dá para fazer 35 ligações por dia se você quiser fazer seu serviço direito" (Entrevista 41, operadora, junho de 2007)

\section{Conclusões}

O setor de serviços tem aumentado sua participação relativa na geração de empregos e de riquezas. Uma especificidade na linha de frente desse trabalho é a duplicidade do controle, de um lado, pela organização normativa e, de outro, pelas necessidades específicas colocadas pelos clientes. $\quad \mathrm{O}$ teleatendimento constitui um dos exemplos desse tipo de atividade, geradora de empregos e, ao mesmo tempo, imbricada em processos de racionalização, nos quais o ritmo de trabalho é intenso e há uma série de regras e normas que padronizam e enrijecem a conduta dos operadores.

O exame da organização do trabalho na empresa pesquisada revelou a coexistência de formas de controle ora mais sutis, ora mais explícitas sobre os operadores. Esse controle assume algumas características semelhantes às discutidas na literatura, como a presença de áreas operacionais amplas e sem paredes que permitem aos superiores observar os operadores e andar entre eles, controlando a atuação de cada um nas baias de atendimento, e, também, o registro de ligações pelos sistemas operacionais, as quais podem ser ouvidas a qualquer momento pelos monitores. A empresa utiliza o script, que visa impor um tratamento padronizado aos inadimplentes durante as ligações e obriga os operadores a permanecer "calmos", mesmo quando em contato com um inadimplente irritado, o que caracteriza a postura de "fachada" apontada por Bateson e Hoffman (2001) e Hochschild (1983).

Há uma imposição de metas crescentes e o controle dentre operadores que compõem a mesma equipe. Essa forma de controle, que vem dos próprios colegas, tem sido apontada pela literatura como mais difusa e distribuída, mas não por isso menos constrangedora. Cumprir as metas representa atender às expectativas da empresa, dos clientes, as próprias e a dos colegas. Sendo assim, os operadores supervisionam a si mesmos e cobram esforços individuais para atingir a produção coletiva. Os entrevistados revelaram a importância de "não fazer corpo mole", de "ter que produzir", caso contrário, "você arrumará problemas com a sua equipe". Ao exercerem controle sobre os colegas, os operadores auxiliam a organização no processo de submissão e disciplina às normas e regras impostas, como ressaltam Alves (2011), Burawoy (1979), Castro e Guimarães (1991) e Zarifian (2001). Observou-se, ainda, o ritmo de trabalho intenso, com curtos intervalos para descanso, como apontado na revisão da literatura sobre teleatendimento. Apesar de todas as restrições, estas não impedem que os operadores desenvolvam suas estratégias de resistência, como apontado por Castro e Guimarães (1991), Dejours 
(1987) e Guerín et al. (2001). Estas estratégias, no entanto, são mais individuais do que coletivas, como apertar a tecla mute, ligar para inadimplentes que nunca atendem e outras, para criar folgas no ritmo de trabalho.

Além dessas formas de controle que confirmam resultados encontrados na literatura, o estudo de caso realizado permitiu identificar formas de controle particulares da empresa pesquisada. Observou-se que a pressão sobre o tempo das ligações fica em segundo plano diante da importância dada ao volume financeiro recuperado, ou seja, ao pagamento de dívidas pelos inadimplentes contatados pelos operadores. Apesar do script, a natureza desse trabalho requer um maior poder de argumentação do operador para conversar com os inadimplentes. Ao mesmo tempo, os bancos clientes impõem quais são as condições para estas negociações. Portanto, os operadores têm uma autonomia limitada e, ainda assim, precisam ter "jogo de cintura" para convencer o inadimplente a aceitar a proposta de pagamento ou refinanciamento dentro das opções pré-determinadas. O processo de cooptação dos operadores é particularmente bem sucedido no esforço da empresa para afastar o estigma negativo do "cobrador", denominando esta função "recuperador de créditos", o que tem sido assimilado pelos operadores e torna mais fácil o cumprimento das regras impostas.

\section{Referências}

ALVES, Giovanni. Trabalho, subjetividade e capitalismo manipulatório: o novo metabolismo social do trabalho e a precarização do homem que trabalha. Estudos do Trabalho, Marília, ano V, n. 8, p. 1-31, 2011.

AZEVEDO, Maria C.; CALDAS, Miguel P. Seriam os Call Centers os Sweatshops do Século XXI? In: ENCONTRO DE ESTUDOS ORGANIZACIONAIS, 2., 2002, Recife. Anais... Recife: Observatório da Realidade Organizacional: PROPAD/UFPE; ANPAD, 2002, 1 CD.

BAGNARA, Sebastiano; MARTI, Patrizia. Human work in call centers: a challenge for cognitive ergonomics. Theoretical Issues in Ergonomics Science, v. 2, n. 3, p. 223-237, jul. 2001.

BARNES, Alison. The construction of control: the physical environment and the development of resistance and accommodation within call centers. New Technology, Work and Employment. v. 22, n. 3, p. 246-259, nov. 2007.

BATESON, John. E. G.; HOFFMAN, Douglas K. Marketing de Serviços. 4 ed. Porto Alegre: Bookman, 2001.

BATT, Rosemary; DOELLGAST, Virginia. Groups, teams and the division of labor. Interdisciplinary perspective on the organization of work. In: ACKROYD, Stephen et al. The oxford handbook of work and organization. Oxford: Oxford University Press, 2005. p. 138-162.

BIAZZI, Fábio de. O trabalho nas organizações na perspectiva sócio-técnica. Revista de Administração de Empresa, São Paulo, v. 34, n. 1, p. 30-37, jan./fev. 1994. Disponível em: < http://www.scielo.br/pdf/rae/ v34n1/a05v34n1>. Acesso em: 29 out. 2017.

BRAGA, Ruy. Uma sociologia da condição proletária contemporânea. Tempo Social, São Paulo, v. 18, n. 1, p. 133-152, jun. 2006. Disponível em: <http://www.scielo.br/scielo.php?script=sci_arttext\&pid=S0103$20702006000100008 \& \operatorname{lng}=p t \& n r m=i s o \& t \operatorname{lng}=p t>$. Acesso em: 29 out. 2017.

BRAVERMAN, Harry. Labor and monopoly capital: the degradation of work in the twentieth century. Nova York: Monthly Review Press, 1974. 
BURAWOY, Michael. Manufacturing consent: changes in the labor process under monopoly capitalism. Chicago: University of Chicago Press, 1979.

A transformação dos regimes fabris no capitalismo avançado. Revista Brasileira de Ciências

Sociais - RBCS, São Pauo, v. 5, n. 13, p. 29-50, 1983.

CALLCENTER. INF. Faturamento bruto e evolução do número de postos de atendimento e operadores dos call centers brasileiros. 2016. Disponível em: $<$ http://ranking.callcenter.inf.br/resumo $>$. Acesso em: jul. 2017. CASTRO, Nadya; GUIMARÃES, Sérgio. Além de Braverman, depois de Burawoy: Novas vertentes analíticas na Sociologia do Trabalho. Revista Brasileira de Ciências Sociais - RBCS, São Paulo, v. 6, n. 17, p. 44-52, 1991. Disponível em: <http://www.anpocs.org.br/portal/publicacoes/rbcs_00_17/rbcs17_04. htm>. Acesso em: 29 out. 2017.

DEJOURS, Christophe. A Loucura do Trabalho. São Paulo: Oboré, 1987. (Estudos de Psicopatologia do Trabalho).

DELBRIDGE, Rick. Life on the line in contemporary manufacturing. Oxford: Oxford University Press, 1998.

DURAND, Jean-P. La chaîne invisible: travailler aujourd'hui, flux tendu et servitude volontaire. Paris: Éditions du Seuil, 2004. p. 107-122.

EDWARDS, Richard C. Contested terrain: The Transformation of the workplace in the twentieth century. Nova York: Basic Books, 1979.

FOUCAULT, Michel. História da sexualidade I: a vontade de saber. 14. ed. Rio de Janeiro: Graal, 2001.

. Vigiar e punir: nascimento da prisão. Petrópolis: Vozes, 1987.

GEORGES, Isabel P. H. Flexibilização do mercado de trabalho e novas formas de mobilidade: carreiras femininas no setor terciário. Revista Latinoamericana de Estúdios del Trabajo, ano 11, n. 18, p. 121-145, 2006. Disponível em: <http://relet.iesp.uerj.br/Relet_18/art6.pdf>. Acesso em: 29 out. 2017.

GITHAY, Leda. Inovação Tecnológica, subcontratação e mercado de trabalho. São Paulo em Perspectiva, São Paulo, v. 8, n. 1, p. 144-153, jan./mar. 1994. Disponível em: <http://produtos.seade.gov.br/produtos/ spp/v08n01/v08n01_16.pdf>. Acesso em: 29 out. 2017.

GRÜN, Roberto. A produção de uma empresa moderna: os bancários e a automação. 1995. Dissertação (Mestrado em Ciências Sociais) - Pontifícia Universidade Católica de São Paulo, São Paulo, 1995.

GUERÍN, François et al. Compreender o trabalho para transformá-lo. A prática da ergonomia. São Paulo: Edgard Blücher, 2001.

GUIA CALL CENTER BRASIL. Informações sobre call center. 2010. Disponível em: <http://www. guiacallcenter.com/>. Acesso em: jan. 2010.

HOCHSCHILD, Arlie R. The Managed Heart. Berkeley and Los Angeles, CA: University of California Press, 1983.

HOLTGREWE, Ursula; KERST, Christian. Flexibility and customer orientation: where does the slack come from? In: WORK, EMPLOYMENT AND SOCIETY CONFERENCE, Nottingham, set. 11-13 September 2001. Disponível em: <http://www.ssoar.info/ssoar/bitstream/handle/document/21686/ssoar-2001holtgrewe_et_al-flexibility_and_customer_orientation_where.pdf?sequence=1>. Acesso em: 29 out. 2017. KORCZYNSKI, Marek et al. Service Work in Consumer Capitalism: Customers, Control and Contradictions. Work, Employment and Society, v.14, n. 4, p. 669-687, dez. 2000.

OLIVEIRA, Sirlei. Reestruturação das telecomunicações no Brasil: uma re(visão) das estratégias de gestão da produção e das relações de trabalho na cadeia produtiva. Estudo de caso da telefonia fixa em São Paulo - 1999 a 2003. 2004. Tese (Doutorado em Sociologia) - Universidade de São Paulo, São Paulo, 2004.

OLIVEIRA, Moacir de M. (coord.) Relatório da Indústria de Call Center no Brasil 2005. The Global Call Center Industry Project. Pontifícia Universidade Católica de São Paulo/Programa de Pós-Graduação em Administração. São Paulo: PUC-SP, 2005. 
ROSENFIELD, Cinara L. Paradoxos do capitalismo e trabalho em call centers: Brasil, Portugal e Cabo Verde. Caderno CRH, Salvador, v. 20, n. 51, p. 447 -462, set./dez. 2007. Disponível em: <http://www.scielo. br/scielo.php?script=sci_arttext\&pid=S0103-49792007000300006>. Acesso em: 29 out. 2017.

SAKAMOTO, Kendi. Como Implementar um Call Center. São Paulo: HappyFew, 2001.

SALERNO, Mario S. Da rotinização à flexibilização: ensaio sobre o pensamento crítico brasileiro de organização do trabalho. Gestão e Produção, São Carlos, v. 11, n. 1, p. 21-32, jan./abr. 2004. Disponível em: <http://www.scielo.br/scielo.php?script=sci_arttext\&pid=S0104-530X2004000100003>. Acesso em: 29 out. 2017.

SALERNO, Mario S. Projeto de organizações integradas e flexíveis: processos, grupos e gestão democrática via espaços de comunicação-negociação. São Paulo: Atlas, 1999.

SEGNINI, Liliana R. P. Relações de gênero e racionalização do trabalho em serviços de atendimento a distância. In: SALERNO, Mario (org.). Relação de Serviço, Produção e Avaliação. São Paulo: Senac, 2001. p. 151-183.

SILVEIRA. Sandra M. Organizações e usos das bases de informação para o atendimento a clientes em call centers. 2006. Dissertação (Mestrado em Ciência da Informação) - Escola de Ciência da Informação, Universidade Federal de Minas Gerais, Belo Horizonte, 2006.

SMITH, Vicki. New forms of work organization. Annual Review of Sociology, v. 23, p. 315-339, ago. 1997.

TAYLOR, Phil; BAIN, Peter. An assembly line in the head: work and employees relation in the call centre. Industrial Relations Journal, v. 30, n. 2, p. 110-117, 1999.

TONET JUNIOR, Celso L. O sentido e a natureza do trabalho de atendimento em call centers: uma análise do discurso organizacional e a percepção de seus operadores de atendimento. 2007. Dissertação (Mestrado em Administração) - Universidade de Brasília, Brasília, 2007.

TRIST, Emery. Evolution of socio-technical systems. Ontario Quality of Working Life Centre, Ontário, v. 2, p. 1-67, 1981. Disponível em: <http://www.lmmiller.com/blog/wp-content/uploads/2013/06/TheEvolution-of-Socio-Technical-Systems-Trist.pdf $>$. Acesso em: jun. 2017.

VENCO, Selma B. Centrais de atendimento: a fábrica do século XIX nos serviços do século XXI1. Revista Brasileira de Saúde Ocupacional, São Paulo, v. 31, n. 114, p.7-18, jul./dez., 2006. Disponível em: <http:// www.scielo.br/scielo.php?script=sci_arttext\&pid=S0303-76572006000200002\&lng=en\&nrm=iso\&tlng= pt>. Acesso em: 29 out. 2017.

Telemarketing, o emprego que desemprega. 1999. Dissertação (Mestrado em Educação) Universidade Estadual de Campinas, Campinas, 1999.

VILELA, Lailah V. de O.; ASSUNÇÃO, Ada Á. Os mecanismos de controle da atividade no setor de teleatendimento: as queixas de cansaço e esgotamento dos trabalhadores. Caderno de Saúde Pública, Rio de Janeiro, v. 20, n. 4, p. 1069-1078, jul./ago. 2004.

ZAMBERLAN, Fabio L.; SALERNO, Mario S. Racionalização e automatização: a organização do trabalho nos bancos. In: FLEUY, Afonso C. C.; VARGAS, Nilton. (org.). Organização do trabalho: uma abordagem multidisciplinar. São Paulo: Atlas, 1983. p. 172-194.

ZARIFIAN, Philipe. Das Mutações do Trabalho à Competência. In: Objetivo Competência: Por uma Nova Lógica. São Paulo: Atlas, 2001. p. 37-65. 